\title{
Experimental and FEM analysis of three carbon steel characterization under quasi-static strain rate for bumper beam application
}

\author{
Dawit Bogale Alemayehu, ${ }^{1, *}$, Song-Jeng Huang ${ }^{2}$, and Ermias Geberekidan Koricho ${ }^{3}$ \\ ${ }^{1}$ Department of Mechanical Engineering, Bahir Dar University, Bahir Dar City, Ethiopia \\ ${ }^{1,2}$ Department of Mechanical Engineering, National Taiwan University of Science and Technology, Taipei, 10607, Taiwan \\ ${ }^{3}$ Department of Mechanical Engineering, Georgia Southern University, Statesboro, GA 30458, USA
}

\begin{abstract}
This paper investigates the mechanical behavior of three selected steel materials which are considered to be the bulk material of front most bumper beam of a vehicle that is suddenly loaded in the quasi-static range. Thirty-six constant strain rate uniaxial tension tests were performed. The test was performed on a HUALONG electro-hydraulic universal testing machine at four strain rates $\left(3.33 \times 10^{-3}, 3.33 \times 10^{-2}, 3.33 \times 10^{-1}, 3.33 s^{-1}\right)$. The FEM which is ABAQUS/CAE is used to simulate the bumper subsystem using the three selected steel. The outcome shows that ultimate tensile strength (UTS) increase with an increase in strain rate and high alloy steel (HAS) material has the maximum mean UTS. The FEM in the post -processing stage gives the minimum displacement and maximum strain energy for HAS material when compared to the other two materials. Finally, from both experimental and ABAQUS explicit analysis the result shows HAS material is better suit for the bumper beam application.
\end{abstract}

\section{Introduction}

Steel is a material used to build the foundations of society. It is an iron-based material containing low amount of carbon and alloying elements that can be made into thousands of compounds with exciting properties to meet a wide range of engineering application. Steel is truly a versatile material. The value of steel produced annually is estimated over 400 billion USD. Thus steel finds its way into the world economy. Nowadays, need of steels is soar up due to newly introduced massive construction projects in civil, mechanical, naval, aeronautical engineering and in other engineering fields. Therefore, it is necessary for designers to understand the dynamic behavior of steel materials.

Bumper beams are designed to with stand the high speed impact from the opposite vehicle or rigid wall during collision and the material to be selected should have a property which can absorb shock load or store strain energy during deformation, this special property is achieved by selecting traditional or reference steel materials with reasonable carbon content.

Recently, considerable attention has been given to the use of steel materials in construction sectors to understand their mechanical and thermo-mechanical behavior under different circumstances. This initiation mainly came from collapse of the two world trade center buildings which were attacked in Sep, 2001 by terrorist. Most of the literatures have concentrated on high-strain rate due to airplane impact and fire impact on the building materials [1].

The study concerns the effect of strain rates caused by dynamically loaded with impacts in the range of $\left(3.3 * 10^{-3}\right.$ to $\left.3.3 \mathrm{~s}^{-1}\right)$ or quasi-static and fire impacts. But the thermal effect (at elevated temperature) is not considered here because the tensile test has been takes place at room temperature. Therefore, the final aim is to increase the strength of this steel products to overcome slow speed impact by absorption of energy through deformation modeling (characterizing) it using numerical and experimental work. And also descriptions of permanent plastic deformations that are designed deliberately in a wide range of industrial processes like automobile industry for this paper, or occur accidentally under undesired overloads. The ABAQUS/CAE software (finite element method) is used to perform reliable simulations of impact experiments that produce plastic deformation in the selected steel specimen from the steel industries in Ethiopia. The numerical model accounts for the actual experimental setup used in the experiments, including testing of the selected items at different strain rate and tensile deformation using universal testing machine performed at room temperature. For the application part the form the car safety part the bumper subsystem is modeled using CATIA/V5 software and exported to ABAQUS/CAE in order to study the effect of strain rate during slow speed impact. Energy absorption from ABAQUS/CAE is compared observed and analyzed as well as the displacement.

In their work, introduce the mechanical properties and microstructures of AISI 4340 high strength alloy steel under different tempering conditions are investigated [2]. They also believe that an understanding of the mechanical properties of metals during deformation over a wide range of loading conditions is of considerable importance for a number of engineering applications. It has been reported that the superiority of super austenitic stainless steel, 254 SMO (S31254), lies in its high strength, good weld ability and great resistance to stress corrosion and pitting because of its higher content of alloying chromium and molybdenum compared to general stainless steel. Furthermore, the

$\overline{{ }^{*} \text { Corresponding author: bogale.sintayehu@gmail.com }}$ 
purpose of this paper is to investigate the effect of strain rate on the mechanical properties and microstructure variation of the super-austenitic stainless steel 254 SMO [3]. The development of physically-based dislocation models of a mechanical response of materials under different strain rates and temperatures is an important problem of modern mechanics. If the microstructure is not affected much by changes in the strain rate and temperature, the models can be employed for predicting mechanical properties of pure metals and alloys under uniaxial loading conditions where in the specimen experiences isotropic homogeneous deformation up to the point of failure solely due to the motion of uniformly distributed defects (dislocations) [4].

One of the defining features of impacts that occur at velocities sufficiently large to cause inelastic (and particularly plastic) deformations is that most of these deformations occur at high strain-rates. These deformations may also lead to large strains and high temperatures. Unfortunately, we do not understand the high-strain-rate behavior of many materials (often defined as the dependence $\sigma_{\mathrm{f}}\left(\varepsilon,{ }^{\circ} \varepsilon, \mathrm{T}\right)$ of the flow stress on the strain, strain rate and temperature), and this is particularly true at high strains and high temperatures. A number of experimental techniques have therefore been developed to measure the properties of materials at high strain-rates. In this section we focus on those experimental techniques that develop controlled high rates of deformation in the bulk of the specimen, rather than those in which high-strain-rates are developed just behind a propagating wave front [6]. The primary experimental techniques associated with the measurement of the rate dependent properties of materials are described in Fig 1 (note that the stress states developed within the various techniques are not necessarily identical). An excellent and relatively recent review of these methods is presented by [7]. For the purposes of this discussion, strain rates above $102 \mathrm{~s}^{-1}$ are classified as high strain rates, strain rates above $104 \mathrm{~s}^{-1}$ are called very high strain rates, and strain rates above $106 \mathrm{~s}^{-1}$ are called ultra-high strain rates. Conventionally, strain rates at or below $10^{-3} \mathrm{~s}^{-1}$ are considered to represent quasi-static deformations, and strain rates below $10^{-6} \mathrm{~s}^{-1}$ are considered to be in the creep domain. Quasi static experiments are typically accomplished through a variety of servo hydraulic machines, and ASTM standards exist for most of these experiments. Most servo-hydraulic ma-chines are unable to develop strain rates larger than $100 \mathrm{~s}^{-1}$ repeatedly, but some specialized servo-hydraulic machines can achieve strain rates of $101 \mathrm{~s}^{-1}$. The primary approach to testing in this strain rate range uses drop towers or drop weight machines [8], and great care must be exercised in interpreting the data because of the coupling between impact-induced wave propagation and machine vibrations. More recently, consideration was given to the impact of the rate of straining of a particular material or component on its performance. Since steel is a strain rate sensitive material, its yield strength increases as the loading rate increases. This provides further benefits in its ability to sustain and absorb higher loads and higher input energy, such as in the case of deformation of a bumper or other structural component. Again, this is not a new discovery but it was only through the introduction of the advanced vehicle concepts phase of the ULSAB (Ultra-Light Steel Auto Body) development that this benefit of steel began to be introduced in structural design of automobile components. Considerable effort was then expended in various laboratories around the world to generate tensile data at straining rates ranging from quasi-static $\left(10-3 \mathrm{~s}^{-1}\right)$ to $103 \mathrm{~s}^{-1}$ for many of the above steel grades [9].

\section{A Bumper system and components}

A bumper is a structure attached to or integrated with the front and rear ends of a motor vehicle, to absorb impact in a minor collision, ideally protecting occupants and minimizing repair costs. The bumper components are shown in the Fig. 1.

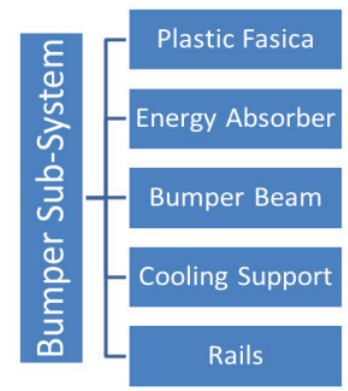

Fig. 1. Automotive bumper system and components.

\section{Methodology}

\subsection{Experimental method}

If a material is to be used as part of an engineering structure that will be subjected to a load, it is important to know that the material is strong enough and rigid enough to withstand the loads that it will experience in service.

\subsubsection{Description of the experiment}

This experiment is done to get the property of the sample materials which are three in number (Low carbon Steel, High Alloy Steel, Medium Carbon Steel). The tension test is done at Addis Ababa Institute of Technology department of mechanical engineering in mechanical workshop. The sample material from the bulk material of the bumper is taken to be tested in our laboratory for tensile strength. The samples are prepared according to ASTM E8 standards in order to achieve the experimental objective. The tensile testing is done using the servo electrohydraulic universal testing machine with data acquisition in order to have the $\mathrm{X}-\mathrm{Y}$ data information during the testing of the specimen. The experiment is done by applying load from the servo hydraulic universal testing machine by applying tension uniaxial load on one side of the specimen and the other side is constrained to 
be fixed. The measurement is taken on the gauge section in which its length is $50 \mathrm{~mm}, 2 \mathrm{~mm}$ thick and $12.5 \mathrm{~mm}$ width.

\subsection{Experimental design}

The experimental design is shown in Table 1, the three $X$ 's each represents the number of samples to be tested for tensile loading for each strain. For instance, MS material is tested three times (XXX) for 3.333*10-3 s-1. It describes the three important parameters such as, the Replica, Factor, and Variable. Here the replica is three for each sample and most importantly the total samples of this testing for the three factors are 36 .

Table 1. Matrix of experimental to be conducted under room temperature.

\begin{tabular}{|c|c|c|c|c|}
\hline Strain rates $\left(\mathrm{s}^{1}\right)$ & $\begin{array}{c}3.33 \\
\times 10^{-3}\end{array}$ & $\begin{array}{c}3.33 \times 10 \\
-2\end{array}$ & $3.33 \times 10^{-1}$ & $\begin{array}{c}3.33 \\
3\end{array}$ \\
\hline $\begin{array}{c}\text { Crosshead }(\mathrm{mm} / \mathrm{m} \\
\text { in) }\end{array}$ & 10 & 100 & 1000 & $\begin{array}{c}1000 \\
0\end{array}$ \\
\hline $\mathrm{MS}$ & $\mathrm{XXX}$ & $\mathrm{XXX}$ & $\mathrm{XXX}$ & $\mathrm{XXX}$ \\
\hline $\mathrm{HAS}$ & $\mathrm{XXX}$ & $\mathrm{XXX}$ & $\mathrm{XXX}$ & $\mathrm{XXX}$ \\
\hline $\mathrm{LCS}$ & $\mathrm{XXX}$ & $\mathrm{XXX}$ & $\mathrm{XXX}$ & $\mathrm{XXX}$ \\
\hline
\end{tabular}

MS=Mild Steel, HAS=High Alloy Steel, LCS=Low Carbon Steel

\subsubsection{Materials used}

The materials under the test are three types in quantity and all are low carbon steel materials. These materials indicated by alphabet $\mathrm{A}(\mathrm{HAS}), \mathrm{B}(\mathrm{LCS})$ and $\mathrm{C}(\mathrm{MS})$ are shown in the Fig.2.

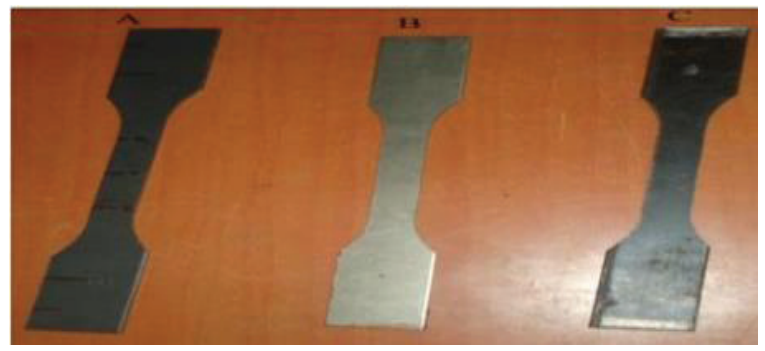

Fig. 2. Specimens "dog bone" used for tensile testing.

\subsection{Finite element modelling}

\subsubsection{Brief introduction to ABAQUS/CAE model}

The simulation work was carried out using commercial software called ABAQUS/CAE which is an engineering tool for programming that is used to solve various degrees of engineering problems ranging from linear to non-linear problems that are complex. ABAQUS/CAE enables models to be solved as quickly as possible by simply importing the geometry under investigation with the right physical and material properties associated to it, meshing it, loading and also by applying the boundary conditions to the material to be modelled [11]. The reference bumper subsystem model was taken from one of the complete FEM car models available in the NHTSA web site and imported into ABAQUS environment.
The 3D part and meshed part that represents the Specimens "dog bone" which is simulated for tension load using ABAQUS/CAE are shown in Fig.3.
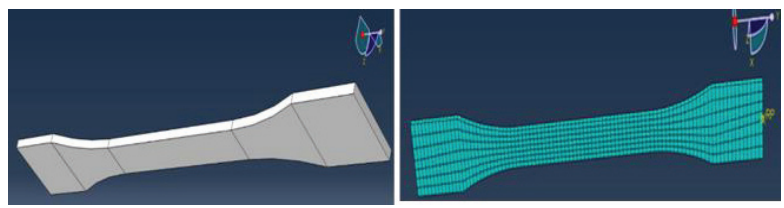

Fig.3. Extruded in $2 \mathrm{~mm}$ thickness specimen model on ABAQUS/CAE and mesh part.

Assembled car bumper system built part by part by CATIA V5 available in the NHTSA web site is shown in Fig. 4 to the left. And this assembled as one part and then saved as STEP* or IGES file extension to be imported to ABAQUS/CAE software for meshing it as desired shown in Fig.4 to the right.
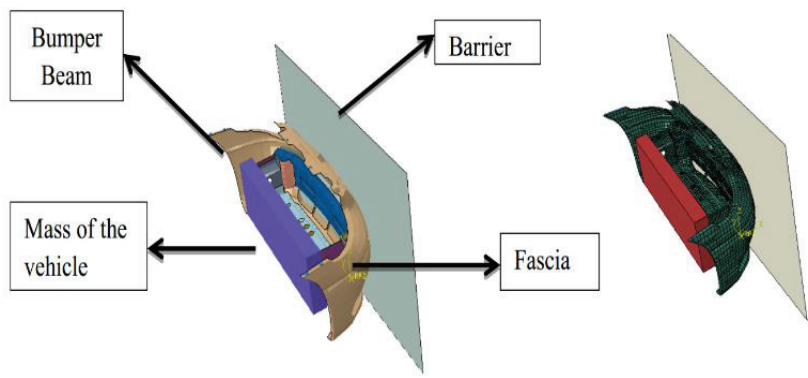

Fig.4. Assembly of the parts and in its initial position and its mesh.

\section{Result and discussion}

\subsection{Results from universal Testing Machine with different Speed}

Fig.5 shows two different results depending on the loading rate or the speed. The three materials to the right is with the same speed so that the resulting displacement is almost the same. At high strain rate the displacement is less and almost at quasi-static strain rate displacement is high.

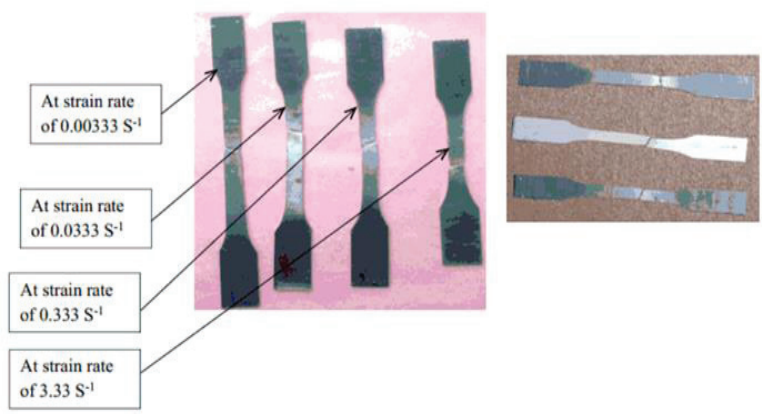

Fig.5. HAS specimen after fracture for different speeds and all samples.

Fig. 6 shows true stress vs. true strain at four different strain rates for the three materials. From this 
figure, the flow stress is increased with the increase of strain rate.
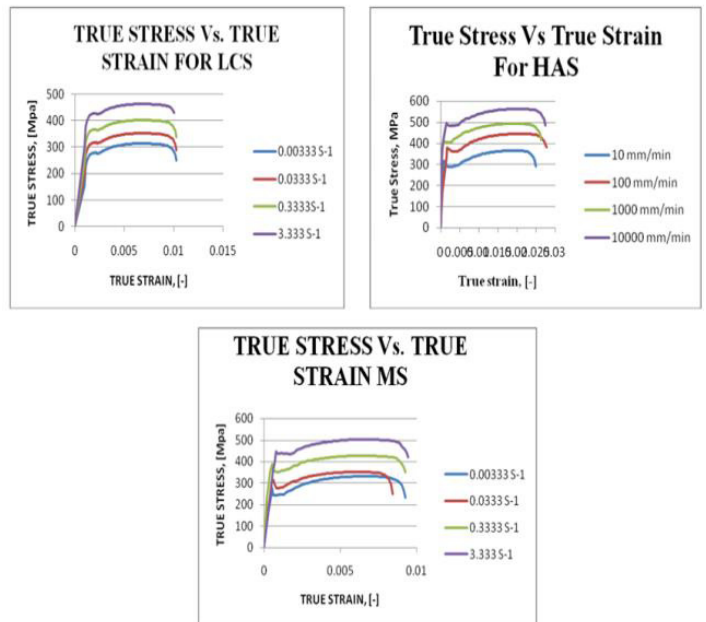

Fig.6. True stress vs. true strain at four different strain rates for the three materials.

From Fig.7, it's indicated that the relation between true stress vs true strain which are the experimental results from the tensile test with different cross head speed of 100,1000 , and $10000 \mathrm{~mm} / \mathrm{min}$. From all the true stress vs true strain curves stated below HAS material has the maximum true ultimate strength as well as maximum yield strength for all strain rate used during the tensile test.
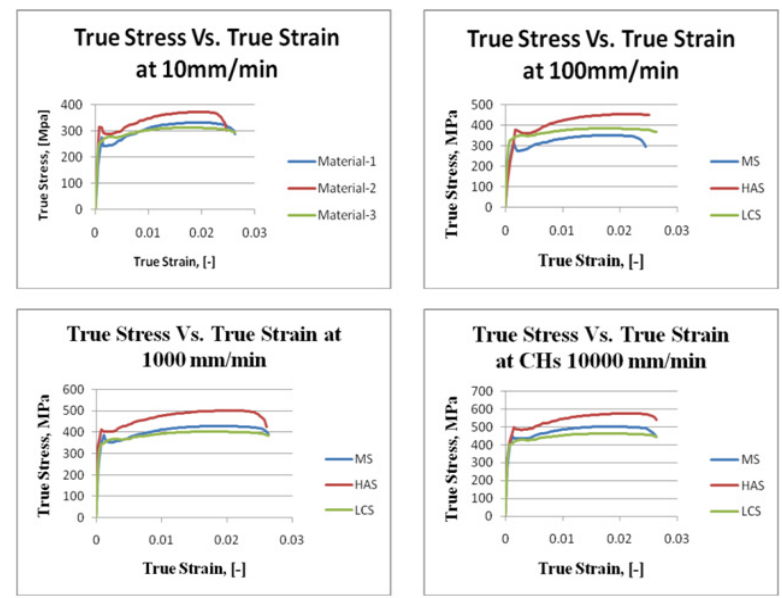

Fig.7. True stress vs true strain for the three materials at $0.00333 \mathrm{~s}^{-1}, 0.0333 \mathrm{~s}^{-1}, 0.333 \mathrm{~s}^{-1}$, and $3.33 \mathrm{~s}^{-1}$ strain rates.

In Fig.8, three materials are compared considering the mean ultimate tensile strength (UTS) for the stated strain rate under study. Among all the three materials HAS shows better improvement in its ultimate tensile strength.
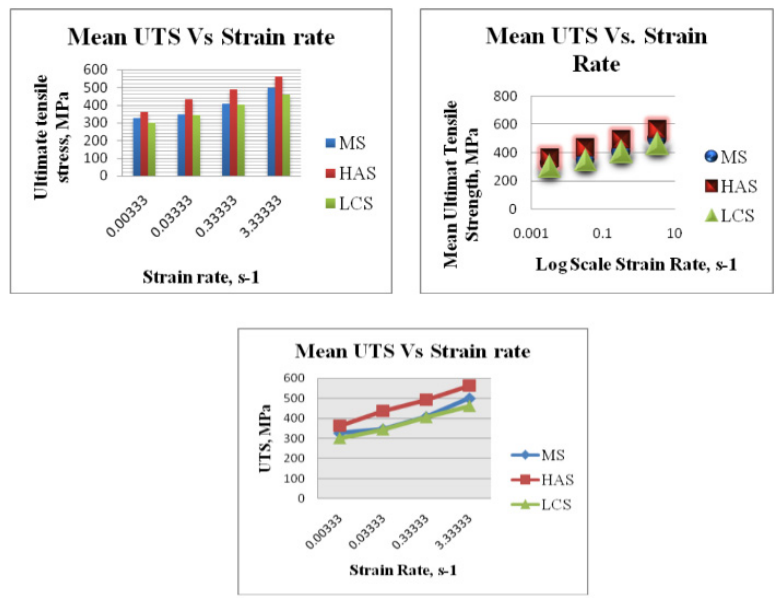

Fig.8. Mean UTS vs. strain rate for the three materials.

\subsection{Results from FEM}

\subsubsection{FEM/ABAQUS/CAE/-explicit analysis result}

Results from visualization module for the sample specimen under study without tensile loading from universal testing machine (to the left: no stress) and increasing application of tensile load (to the right: with highly stressed in the gauge region) are indicated in Fig.9.

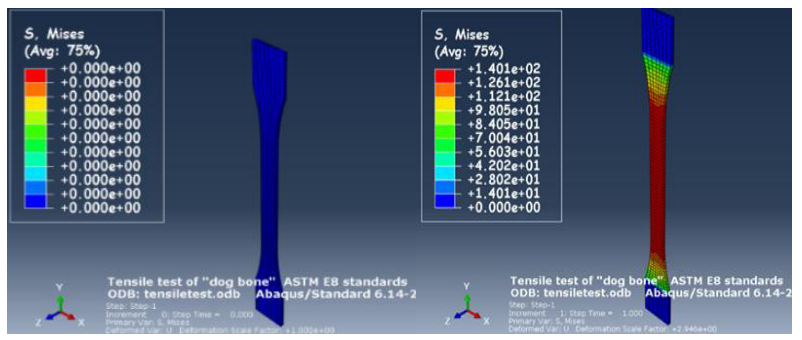

Fig.9. The displacement counter for sample specimen.

Fig.10 shows the velocity magnitude and displacement magnitude for the bumper system which is meshed in ABAQUS/CAE and analyezed for low speed impact. As it is expected in the real scenario and literature results the car will have decelerated after collision and the velocity magnitude will be lower.

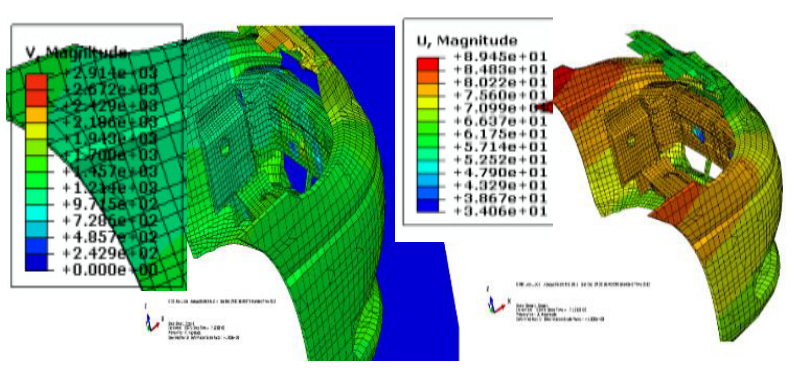

Fig.10. Displacement counter for the whole bumper energy absorber system. 


\subsubsection{The Bumper subsystem ABAQUS/CAE result}

The results are from the ABAQUS/CAE for the overall displacement of the bumper system after low velocity impact for LCS which higher when compared to the other two sample materials with lower energy storing capability shown in Fig. 11.

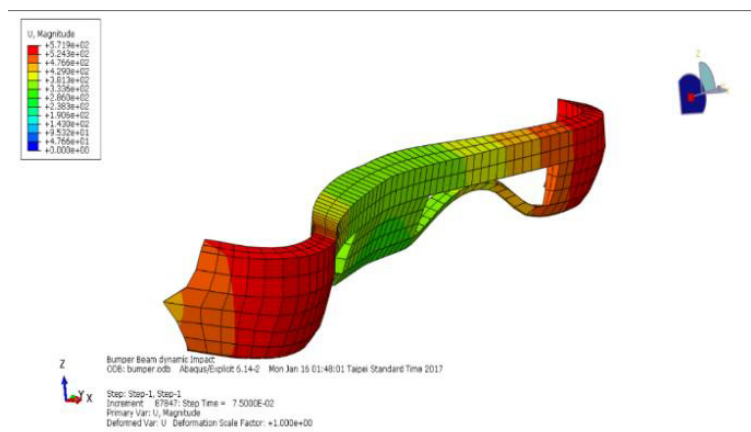

Fig.11. Displacement counter plot for bumper beam with foam.

\subsubsection{The strain-energy plot from the ABAQUS/CAE visualization}

Fig.12 shows that the displacement and the strain energy stored in the bumper beam during deformation after collision or impact takes place. As it is observed from both diagrams from all the three sample materials considered in this paper high alloy steel (HAS) show lower deformation and higher strain energy during straining of the bumper under low speed impact which occurred during indoor test.
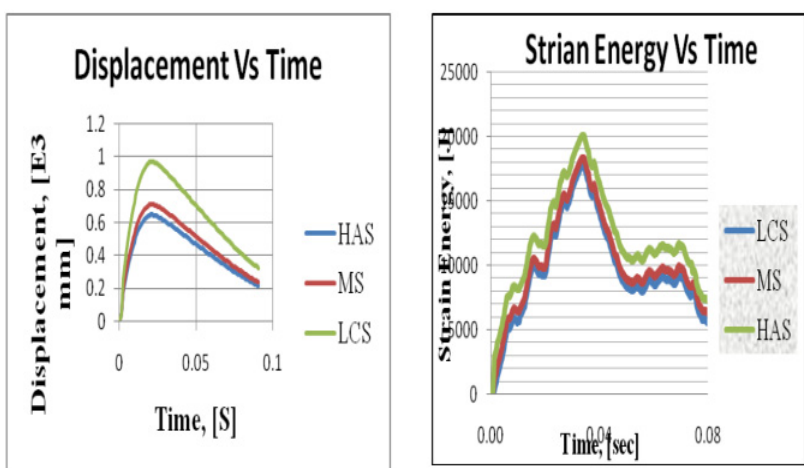

Fig.12. Strain energy vs time for the three sample steel materials.

\section{Conclusion}

In this study three different materials-namely low carbon steels (LCS, HAS, and MS) have been evaluated for the bumper beam, to understand the effect of strain rate on a crash behaviour of automobile during low speed frontal crash test performed by 36 -sample specimen test in the experiment for tension at different strain rate and the data used as input to numerical simulation with ABAQUS code.
To study the steel material for bumper beam, two different factors are considered; strain rate and material type. When the materials are tested under different strain rate for their mechanical behaviours such as yield stress and ultimate tensile strength it is observed that both the yield stress and mean UTS of the material shows positive response with the strain rate; as the strain rate increases the mean yield stress and the mean UTS increases. And material two shows $20 \%$ increase in its UTS and $14 \%$ of its yield strength when compared to the other two steel material. Hence from the experimental result HAS improves the crash worthiness and shows better mechanical responses for such application relative to the other two materials under investigation.

On the other hand, from the FEM the ABAQUS/CAE result the displacement and strain energy are plotted against the time during low speed impact of the bumper subsystem for the three low carbon steel. HAS absorbs more energy and shows low deformation or has the minimum displacement when it applied with dynamic loading and from this for this quasi-static strain rate HAS has best mechanical behaviour as compared to the other two steel materials for this low speed impact.

\section{References}

1. American Iron and Steel Institute, Steel bumper systems for passenger cars and light trucks report. American Iron and Steel Institute (2006)

2. American Iron and Steel Institute, Steel bumper system for passengers vehicles and light tracks Report. Southfield, Michigan 48075: (2006)

3. Chia, C.W. et al., Inverse effect of strain rate on mechanical behavior and phase transformation of super austenitic stainless steel, Scripta Materialman, 17-20 (2007)

4. Coffey, C.S. \& Davos, V.F., Drop weight impact machines: a review of recent progress, In Ramesh, K.T., ed. JANNAF Propulsion Systems Hazards Subcommittee Meeting, (1986)

5. Council, A.C., Automotive Plastic. [Online] (2) Available at: http://www.plasticscar.com/bumpers (Accessed 29 January 2013)

6. Field, J.E., Review of experimental techniques for high rate deformation and shock studies, Int. J. Imp. Eng., 30,725-775(2004)

7. M. Vural, D. Rittel \& G. Ravichandran, Large strain mechanical behavior of 1018 cold-rolled steel over a wide range of strain rates, Metallurgical and Materials Transactions, 34A(A), 2873-2885(2003)

8. Ravi Yatnalkar, B.E. , Experimental investigation of plastic deformation of Ti-6Al-4V under various loading conditions, Masters. Ohio: The Ohio State University The Ohio State University (2010)

9. Simulia, D.S., Abaqus Analysis User's Manual. 1st ed. Chicago: Simulia Software company (2010)

10. Springer, High strain rate and impact experiments. in K.T. Ramesh, ed. Springer Handbook of 
Experimental Solid Mechanics. New York: W.N. Sharpe, Jr 3,1-29 (2008)

11. Woei, S.L. \& Tzay, T.S., Mechanical properties and microstructure of AISI 4340 high strength alloy steel under tempering condition. ELSEVIER, 198199 (1997) 